\title{
Tamoxifen Improves Cholinergically Modulated Cognitive Performance in Postmenopausal Women
}

\author{
Paul Newhouse*,1,2, Kimberly Albert', Robert Astur ${ }^{3}$, Julia Johnson ${ }^{4}$, Magdalena Naylor ${ }^{2}$ and Julie Dumas ${ }^{2}$ \\ 'Vanderbilt Center for Cognitive Medicine, Department of Psychiatry, Vanderbilt University School of Medicine, Nashville, TN, USA; ${ }^{2}$ Clinical \\ Neuroscience Research Unit, Department of Psychiatry, University of Vermont College of Medicine, Burlington, VT, USA; ${ }^{3}$ Department of \\ Psychology, University of Connecticut, Storrs, CT, USA; ${ }^{4}$ Department of Obstetrics and Gynecology, University of Massachusetts School of \\ Medicine, Worcester, MA, USA
}

\begin{abstract}
Tamoxifen (TMX) is a selective estrogen receptor modulator that is used as an estrogen receptor antagonist for the treatment and prevention of breast cancer. Whether TMX has antagonist activities in the human brain is less clear and its effects on cognitive function have not been experimentally explored. This study examined how TMX affected cognitive performance in older women using a model of anticholinergic drug-induced cognitive dysfunction. Twenty-one postmenopausal women were administered $20 \mathrm{mg}$ of oral TMX or placebo for 3 months. Participants then took part in five drug challenges using the anticholinergic antinicotinic agent mecamylamine (MECA) and antimuscarinic agent scopolamine (SCOP) and were tested on a comprehensive battery including tasks of attention and psychomotor function, verbal episodic memory, and spatial navigation. After a 3-month placebo washout, participants were then crossed over to the alternate treatment and repeated the drug challenges after 3 months. Compared with placebo treatment, TMX significantly attenuated the impairment from cholinergic blockade on tasks of verbal episodic memory and spatial navigation, but effects on attentional/psychomotor tasks were more variable. Analysis by APOE genotype showed that APO $\varepsilon 4+$ women showed a greater beneficial effect of TMX on reversing the cholinergic impairment than APO $\varepsilon 4$ - women on most tasks. This study provides evidence that TMX may act as an estrogen-like agonist to enhance cholinergic system activity and hippocampally mediated learning. Neuropsychopharmacology (2013) 38, 2632-2643; doi: I0.1038/npp.2013.172; published online 7 August 2013
\end{abstract}

Keywords: acetylcholine; cognition; menopause; mecamylamine; scopolamine; tamoxifen

\section{INTRODUCTION}

Complaints of cognitive decline are common during and following menopause in women (Weber and Mapstone, 2009), and are likely related to the decline in circulating estrogen. Although research into the effects of hormone treatment on cognition has been conflicting, a meta-analysis of clinical trials (Maki, 2005) offered consistent evidence that estrogen therapy without concurrent progesterone may improve or maintain cognitive performance following menopause. The use of estrogen therapy is limited by its effects on peripheral tissues; estrogen treatment is thus not appropriate for women at risk for some cancers and cardiovascular disease (Collaborative GoHFiBC, 1997; Ewertz et al, 2005; Hulley and Grady, 2004; Manson et al, 2007; Rossouw et al, 2002; Rossouw et al, 2007; Wassertheil-Smoller et al, 2003).

Selective estrogen receptor modulators (SERMs) hold the promise of selective activation of estrogen receptors in

*Correspondence: Dr P Newhouse, Vanderbilt Center for Cognitive Medicine, Department of Psychiatry, Vanderbilt University School of Medicine, 1601 23rd Avenue, Nashville, TN 37212, USA, Tel: + | 6159360928 , Fax: + | 615875 0686,

E-mail: paul.newhouse@vanderbilt.edu

Received 12 April 2013; revised 25 June 2013; accepted 2 July 20 I3; accepted article preview online 19 July 2013 different tissue types. This may allow activation of estrogen receptors in the brain with beneficial effects on cognition while avoiding potential harmful effects in peripheral tissues. However, little is known about the effects of SERMs in the brain, especially in healthy participants. The main clinical application of SERMs is preventing breast cancer recurrence in patients with estrogen receptor-positive tumors. These studies are often confounded by both cancer history and chemotherapy treatment, both of which are suggested to have effects on cognition (Falleti et al, 2005).

Examining the effects of SERMs in healthy postmenopausal women will be important in developing alternative or augmentative strategies to traditional hormone treatment. Tamoxifen (TMX) is a SERM that has been used for its estrogen antagonistic effects on breast tissue (Osborne, 1998; Ward, 1973), but it also has agonist effects in other tissues such as bone (Kristensen et al, 1994). TMX treatment may be extended to at least 10 years to reduce the risk of breast cancer recurrence (Powles, 2012). Thus, the impact of TMX on brain systems is important to study as activity on CNS systems that express estrogen receptors (ERs) might have significant impact on long-term cognitive and/or behavioral integrity, raising questions similar to those raised regarding long-term use of estrogen treatment on cognitive functioning (Coker et al, 2010). 
Although the effects of TMX in the central nervous system remain to be fully understood, there is evidence that they may depend on the availability of estrogen. In estrogendeprived animal models, TMX has effects similar to that of estrogen on brain morphology (Gonzalez-Burgos et al, 2012; Silva et al, 2000), and is associated with estrogen-like effects on markers of neuroprotection (Sharma and Mehra, 2008) and in brain morphology in postmenopausal women (Ernst et al, 2002). In intact male (Esmaeili et al, 2009) and female (Chen et al, 2002) rodents, TMX treatment is associated with reduced memory consolidation and retrieval. However, in ovariectomized (Velazquez-Zamora et al, 2012) and orchiectomized (Lagunas et al, 2011) rodents, TMX has effects similar to that of estrogen treatment in improving memory performance. Human studies examining the effects of TMX in the brain are few, and confounded by cancer history, chemotherapy treatment, hormonal status, and age (Palmer et al, 2008). Despite these limitations, evidence is emerging, consistent with animal studies, that the effects of TMX in the brain may be dependent on whether TMX competes with estrogen or acts alone (Brinton, 2002).

Studies in our (Dumas et al, 2008; Dumas et al, 2006; Dumas et al, 2012) and other labs revealed that estrogen acts in part through the cholinergic system to benefit cognition (as reviewed by Gibbs (2010)). Estradiol reduced the effects of nicotinic and muscarinic acetylcholine antagonism on tests of attention and verbal learning and memory (Dumas et al, 2008; Dumas et al, 2006). TMX has estrogen-like effects on the central, cholinergic system, supporting the possibility of estrogen-like enhancements on cognition (McMillan et al, 2002). Both estradiol treatment and TMX, given at clinically relevant doses, restored choline acetyltransferase (ChAT) activity reduced by ovariectomy in the hippocampus to pre-ovariectomy levels (Wu et al, 1999) and in the nucleus basalis of Meynert (McMillan et al, 2002).

Using an established model (Dumas et al, 2008; Dumas et al, 2006; Dumas et al, 2012) to show the effects of estradiol on cholinergic-related cognitive functioning, the study presented here examined whether cognitive impairments caused by cholinergic antagonists in healthy postmenopausal women were affected by 3 months of prior TMX treatment. Participants completed evaluations of attention, verbal memory and spatial learning and memory under the influence of a placebo or a muscarinic (scopolamine; SCOP) and/or nicotinic (mecamylamine; MECA) acetylcholine antagonist. We hypothesized that TMX would, in the absence of estrogen, enhance cholinergic function and reduce the effects of muscarinic and nicotinic blockade on attention, episodic memory, and spatial learning and memory. Further, TMX effects on cognition may diverge depending on apolipoprotein E (APOE) status. At least one APO 84 allele in healthy postmenopausal women prevented cognitive benefit from estrogen treatment (Yaffe et al, 2000) and led to cognitive impairment following estrogen treatment (Kang and Grodstein, 2012). If TMX acts similarly to estrogen in the brain, it might be expected that APO \&4-positive women would show different effects on cholinergically mediated cognitive performance following treatment than APO 84 -negative women. Because of this possibility, taken together with the findings that APOE genotype has a significant influence on cognitive aging (Bretsky et al, 2003), especially in women (Mortensen and
Høgh, 2001), we decided to examine the results in terms of the subject's APOE genotype.

\section{METHODS}

The study was reviewed and approved by the University of Vermont Committee for Human Research in the Medical Sciences. All participants provided informed consent.

\section{Participants}

Participants were cognitively normal, physically healthy postmenopausal women. Participants were required to be postmenopausal, without menses for 1 year, without surgically induced menopause, non-smokers, no history of breast cancer, and no use of hormone therapy for at least 1 year. Medical exclusion criteria for TMX were identical to those detailed in the study of Dumas et al (2006) for estradiol and anticholinergic drug treatment. Additional exclusions included heavy alcohol or coffee use or current Axis I psychiatric disorders.

Upon meeting these criteria, participants were approved for further screening at the Clinical Research Center (CRC). Participants provided their medical history, underwent physical and laboratory tests assessing hematopoietic, renal, hepatic, and hormonal function. Each participant provided a blood sample for APOE genotyping. Each woman was cognitively evaluated, as discussed by Dumas et al (2006), to ensure normal cognitive performance, to be as cognitively similar as possible, and were required to have an Mini Mental State Exam score $\geqslant 27$, a Dementia Rating Scale score of $>123$, and a Global Deterioration Scale score of 1 or 2.

Behavioral screening consisted of a partial Structured Clinical Interview for DSM-IV-TR (SCID; First et al, 2001). In addition, participants completed the Beck Depression Inventory (BDI; Beck et al, 1961) with an exclusion cutoff score of 10 .

\section{Tamoxifen Administration}

After meeting all the inclusion criteria, participants were randomly and blindly assigned to tamoxifen or placebo treatment for the first 3 months (Phase 1). In the TMX condition, participants received $20 \mathrm{mg}$ of oral TMX per day for 3 months. This period of drug administration was chosen to be comparable with our prior studies examining the effects of estrogen on cholinergic functioning (Dumas et al, 2008; Dumas et al, 2006). In the placebo condition, the participants received similar-appearing placebo pills. After the 3 months of treatment, women completed 5 challenge days (described below). Subsequent to the challenge phase, participants were washed out for 3 months with the placebo, then crossed over to the other condition for another 3 months (Phase 2), and then completed 5 more challenge days identical to Phase 1 . See Figure 1 for detailed design.

\section{Cholinergic Challenge Procedure}

Following 3 months of TMX or placebo, subjects returned to the CRC and participated in 5 cholinergic challenge study days as detailed in the study by Dumas et al (2006). A double-blind, double-placebo-randomized method of administration of the challenge drugs was followed. The 


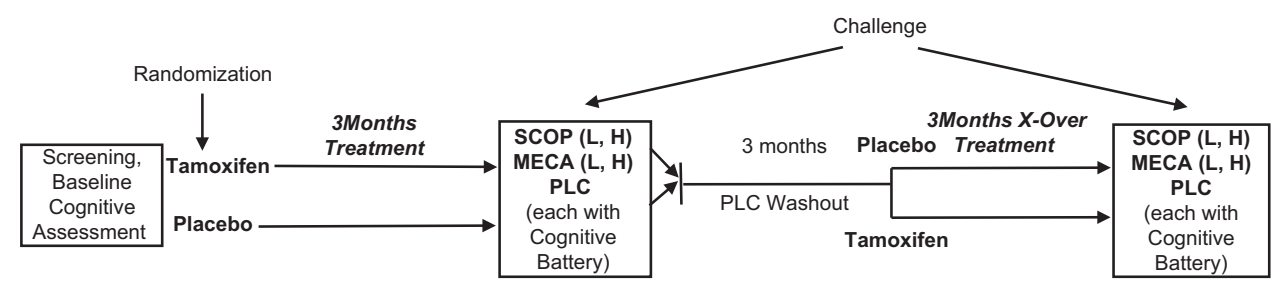

Figure I Design of study. Challenge=drug challenge phase. SCOP=scopolamine; $L=2.5 \mu \mathrm{g} / \mathrm{kg} ; \mathrm{H}=5.0 \mu \mathrm{g} / \mathrm{kg}$. MECA $=$ mecamylamine; $\mathrm{L}=10 \mathrm{mg}$; $\mathrm{H}=20 \mathrm{mg}$. $\mathrm{PLC}=$ placebo. Total time period for the study was $\sim 10$ months.

participants received one of the following medications: $2.5 \mu \mathrm{g} / \mathrm{kg}$ or $5 \mu \mathrm{g} / \mathrm{kg}$ IV SCOP, $10 \mathrm{mg}$ or $20 \mathrm{mg}$ oral MECA, or placebo. At time 0 , a pill was administered containing MECA or placebo. Thirty minutes later, an injection of SCOP or placebo was administered intravenously. Ninety minutes after the injection and 120 min after oral pill administration, cognitive testing began. Vitals signs and pupil diameters were assessed at $0,30,60,120,180,210$, and $240 \mathrm{~min}$.

\section{Cognitive Battery}

The cognitive testing battery was constructed to evaluate a number of cognitive domains potentially sensitive to cholinergic manipulation including tests of attention, verbal learning and memory, and spatial learning and memory. Before each of the challenge phases, participants were trained on the cognitive battery to minimize learning or practice effects.

Attention. The choice reaction time (CRT) task (Dumas et al, 2006; Hindmarch, 1984) was used as the measure of attention. Performance measures included the median total reaction time (RT), the median recognition $\mathrm{RT}$ (time from stimulus onset to initiation of movement), and the median motor RT (time from initiation of movement to stimulus termination).

Verbal memory. Short-term memory: digit span (DS): participants were presented with a series of digits (eg, 8, 3, 4) and were asked to immediately repeat them back. Participants were started with short sets and after successfully completing three of a particular set size, another item was added. The digit span score was the total number of lists successfully completed.

Semantic memory (fluency): participants were instructed to generate as many unique words as possible beginning with the letter ' $F$ ' in $60 \mathrm{~s}$. Similarly, they then were asked to generate words with ' $A$ ' and ' $S$ '. The score was the total of all unique words generated.

Verbal episodic memory: the Buschke selective reminding task (SRT; Buschke, 1973) was used as a measure of verbal episodic memory. In the SRT, participants were read a list of 16 words, followed by an immediate recall trial. On subsequent trials (up to 8), participants were immediately reminded of words they had failed to recall on the prior trial. There were two delayed recall trials. Four measures were obtained from the SRT task: the total number of words recalled across all lists, recall consistency, recall failure, and delayed recall.
Spatial learning and memory. Virtual Morris water maze (Astur et al, 1998; Newhouse et al, 2007) was used as the measure of spatial navigation and learning. Participants sat in front of a $17^{\prime \prime}$ computer screen; they were told to use the joystick to move around the pool and that the computer would give them visual and auditory feedback when they had escaped. They were also explicitly informed that the platform would remain in the same location during each trial. There were 4 blocks of 4 hidden platform training trials (16 total), with the participants starting from four different locations (north, south, east, and west) followed by a probe trial in which the platform was removed from the pool; the participants were placed in the south starting location and were allowed to search for the platform for $30 \mathrm{~s}$. After the probe trial, the platform was moved to a different location in the pool (the center of the NW quadrant) and was raised slightly out of the water so that it would be visible to the participant.

The cognitive tasks were administered in the following order: SRT, virtual Morris water maze (VMWM), SRT Delayed Recall 1, Fluency, Implicit memory (not reported here), CRT, DS, and SRT Delayed Recall 2. A minimum of 12 equivalent versions of the testing forms were created so that a new version of each test was available for each of the testing days ( 5 challenge days for Phase 1 and Phase 2 plus training before each phase). These forms were counterbalanced across study days for all participants.

Behavioral measures. After the cognitive battery was completed, participants completed behavioral assessment measures including the Profile of Mood States (POMS; McNair et al, 1971), Stanford Sleepiness Scale (Hoddes et al, 1973), Subjective Visual Analog Scale (SVAS; Newhouse et al, 1994), and a Physical Symptom Checklist (PSCL). The experimenter completed the Brief Psychiatric Rating Scale (BPRS; Overall and Gorham, 1993) and Objective Visual Analog Scale (OVAS; Newhouse et al, 1994).

\section{Data Analysis}

Our main analysis of interest was whether 3 months of TMX treatment would lessen the negative effects of the antimuscarinic and antinicotinic drugs on the cognitive tasks in this study. Analysis of the placebo challenge days between TMX phases did not reveal any significant differences across the cognitive tasks. Thus, there were no significant effects of TMX treatment alone (without anticholinergic challenge) on cognitive performance. To then analyze the interactive effects of TMX and anticholinergic challenge agents, we calculated difference scores for each of the 
dependent measures from each task. Performance on the cholinergic challenge placebo day was subtracted from performance on each of the other cholinergic challenge days (within a phase) in an effort to control for anticipated baseline differences in performance for different participants in different phases of the study (see Table 1). The effects of SCOP and MECA were analyzed in separate models in order to examine the effects of TMX on antimuscarinic- and antinicotinic-induced cognitive impairment, behavioral changes, and vital signs, separately. For the SCOP challenge days, 2 (TMX treatment: TMX vs PLC) $\times 2$ (SCOP dose: $2.5 \mu \mathrm{g} / \mathrm{kg} v s 5.0 \mu \mathrm{g} / \mathrm{kg}) \times 2(\mathrm{APOE}$ $\varepsilon 4$ : APOE $\varepsilon 4+v s$ APOE $\varepsilon 4-)$ mixed model ANOVAs were run for each dependent measure. For the MECA challenge days, 2 (TMX treatment: TMX vs PLC) $\times 2$ (MECA dose: $10 \mathrm{mg} v s 20 \mathrm{mg}) \times 2(\mathrm{APOE} \varepsilon 4:$ APOE $\varepsilon 4+v s$ APOE $\varepsilon 4-)$ mixed model ANOVAs were run for each dependent measure. If TMX altered the negative effects of the anticholinergic drugs on cognition, then main effects of TMX would be seen in these analyses. For the VMWM, the data for the mean latency and distance to swim to the hidden and visible platforms across blocks of trials were analyzed with repeated measures ANOVAs across blocks of four trials each.

\section{RESULTS}

\section{Participants}

Participants were 21 cognitively normal women (ages: 50$74 ; M=60.8 ; \mathrm{SD}=7.5)$. These women were postmenopausal for an average of 13 years since their last menses $(\mathrm{SD}=11.9)$ and had been off any hormone treatment for an average of 11.3 years $(S D=11.2)$. Eleven women had previously taken hormone or estrogen therapy after menopause. The length of time of prior hormone use ranged from 2 weeks to 10.5 years. They had a mean body mass index (BMI) of 26.7 $(\mathrm{SD}=4.8)$. Subjects had an average of 15.8 years of education $(\mathrm{SD}=2.1)$. APOE genotyping showed the following breakdown: APOE $\varepsilon 2 / 2=0$; $A P O E ~ \varepsilon 2 / 3=1$, APOE $\varepsilon 2 /$ $4=1$, APOE $\varepsilon 3 / 3=11$; and APOE $\varepsilon 4 / 3=7$, APOE $\varepsilon 4 / 4=0$.

\section{Cognitive Battery}

Attention/psychomotor function: choice RT. Both anticholinergic challenge agents increased total median RT. There was a main effect of SCOP dose on median RT ( $F(1$, $18)=22.05, p<0.001)$. There was also a SCOP dose by APOE4 genotype interaction $(F(1,18)=4.57, p=0.05)$. Post hoc $t$-tests showed that high-dose SCOP increased total median RT more than low-dose SCOP for both the APOE $\varepsilon 4+(t(14)=2.8 ; p=0.01)$ and APOE $\varepsilon 4-(t(22)=4.15$, $p<0.001$ ) groups (see Figure 2). For MECA, there was a significant treatment by challenge interaction $(F(1$, $18)=4.83, p=0.05)$. Post hoc $t$-tests showed a trend for TMX to reduce the impairing effects of low-dose MECA compared with placebo treatment $(t(21)=2.00, p=0.06)$. There was also a trend for an interaction of MECA dose and APOE4 genotype $(F(1,18)=4.17, p=0.056)$. The pattern of means showed that APOE $\varepsilon 4+$ women had greater reduction of total median RT under high dose-MECA.
Decomposing total RT into motor and recognition components showed that there was a main effect of treatment $(F(1,12)=7.59, p=0.02)$, with TMX increasing the effect of SCOP on motor RT. There was an interaction of SCOP dose and APOE4 genotype on motor RT $(F(1,18)=13.96, \quad p=0.01)$. High-dose SCOP increased motor median RT greater than low-dose for APOE $\varepsilon 4-$ $(t(22)=3.55, \quad p=0.002) \quad$ and APOE $4+\quad(t(14)=2.62$, $p=0.02$ ) women. For MECA, there was a trend for a treatment by MECA dose interaction $(F(1,18)=4.25$, $p=0.054$ ), with TMX reducing the effect of high-dose MECA on motor RT. There was also an interaction of MECA dose and APOE4 genotype $(F(1,18)=6.41, p=0.02)$, with a trend for low MECA to produce a longer median motor RT for the APOE $\varepsilon 4-$ group compared with the APOE $\varepsilon 4+$ group $(t(14)=1.99, p=0.07)$. There was a main effect of TMX $(F(1,18)=15.91, p<0.01)$ with a longer recognition $\mathrm{RT}$ after SCOP.

\section{Memory}

Short-term memory: digit span. Anticholinergic drug challenge impaired performance on this measure with a main effect of SCOP dose $(F(1,18)=5.95, p=0.03)$. MECA also tended to impair performance, but the effects were nonsignificant. There were no significant main effects of TMX treatment or treatment by challenge interactions.

Semantic memory: verbal fluency. SCOP produced no significant effects on this task. However, after MECA challenge, there was a significant TMX treatment by MECA dose interaction $(F(1,18)=9.64, p=0.01)$. Post hoc $t$-tests showed a trend for TMX to reduce the impairing effects of MECA on verbal fluency more for high-dose MECA $(t(19)=1.96, p=0.06)$.

Verbal episodic memory: Selective Reminding Task: anticholinergic drug challenge reduced performance in verbal episodic memory during the SRT task in a predictable manner with significant main effects of SCOP dose on all measures: eight-trial recall $(F(1,18)=56.67$, $p<.001)$, recall failure $(F(1,18)=26.83, p<.001)$, and consistency $(F(1,18)=45.35, p<.001)$. There was a trend for an interaction of TMX treatment and SCOP dose on eight-trial consistency $(F(1,18), 3.86, p=0.07)$. The pattern of means showed that TMX tended to reduce the impairing effects of SCOP. For the second delayed recall measure, there was a TMX treatment main effect $(F(1,16)=5.69$, $p=0.04)$ that showed TMX treatment reduced the impairing effects of SCOP compared with placebo (Figure 3). There was also a TMX treatment by SCOP dose interaction $(F(1$, $16)=5.69, p=0.03$ ) with a trend for TMX to lessen the impairment of low-dose SCOP $(t(19)=1.95, p=0.07)$.

The impact of the nicotinic antagonist MECA was smaller. For the second delayed recall, there was a main effect of TMX treatment $(F(1,15)=5.90, p=0.03)$ that showed TMX treatment reduced the effects of MECA compared with placebo.

\section{Spatial Navigation and Memory: VMWM}

There was a main effect of SCOP dose on latency to find the hidden platform $(F(1,18)=6.45, p=0.02)$, which showed 
Table I Performance Differences for Cognitive Tasks for Each Drug Challenge by Treatment Type by APOE Genotype

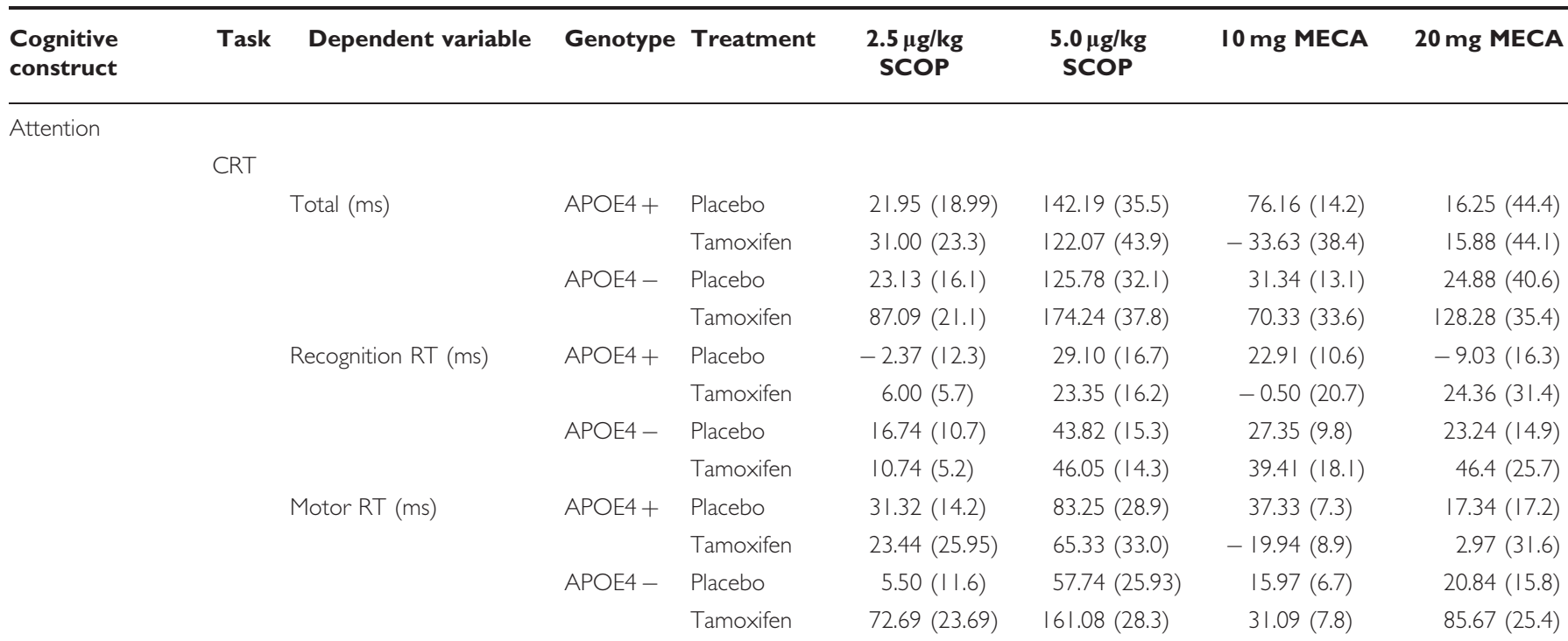

Short-term

memory

DS

\begin{tabular}{|c|c|c|c|c|c|c|}
\hline \multirow{4}{*}{$\begin{array}{l}\text { Digit span (number } \\
\text { correct) }\end{array}$} & $\mathrm{APOE} 4+$ & Placebo & $0.86(0.7)$ & $-0.25(0.6)$ & $0.59(0.5)$ & $-0.78(0.6)$ \\
\hline & & Tamoxifen & $0.25(0.6)$ & $-0.63(0.6)$ & $0.50(0.7)$ & $0.13(0.7)$ \\
\hline & APOE4 - & Placebo & $0.33(0.5)$ & $-0.75(0.5)$ & $-0.08(0.4)$ & $0.27(0.5)$ \\
\hline & & Tamoxifen & $0(0.5)$ & $-0.9 \mid(0.5)$ & $-0.28(0.6)$ & -0.650 \\
\hline
\end{tabular}

Semantic memory

FT

Words generated

$$
\begin{aligned}
\text { APOE4 }+\quad & \text { Placebo } \\
& \text { Tamoxifen } \\
\text { APOE4 - } \quad \text { Placebo } & \text { Tamoxifen }
\end{aligned}
$$

Placebo

Episodic memory

SRT
APOE4+ correct)

Recall failure (number of failures)

Delayed recall I (number
correct)

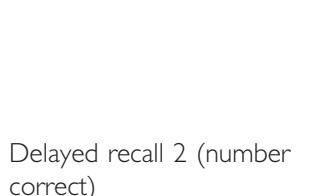

Recall consistency (number APOE4+ correct)

Recall failure (number of
failures)

$1.29(2.3)$
$1.13(2.1)$
$3.63(1.8)$
$-0.18(1.8)$

$$
\begin{array}{r}
-0.13(2.1) \\
-1.00(2.1) \\
0.25(1.8) \\
-1.09(1.8)
\end{array}
$$

\begin{tabular}{|c|c|c|c|c|c|}
\hline & Tamoxifen & $-7.63(4.4)$ & $-24.75(4.4)$ & $4.25(5.9)$ & $-1.88(4.4)$ \\
\hline \multirow[t]{2}{*}{ APOE4 - } & Placebo & $-10.58(3.6)$ & $-24.42(3.6)$ & $-7.83(4.8)$ & $-7.19(3.7)$ \\
\hline & Tamoxifen & $-3.80(4.0)$ & $-16.70(4.0)$ & $-3.02(5.1)$ & $-0.97(3.9)$ \\
\hline \multirow[t]{2}{*}{ APOE4 + } & Placebo & $8.49(4.7)$ & $26.75(4.4)$ & $5.74(3.44)$ & $3.14(3.3)$ \\
\hline & Tamoxifen & $6.38(4.4)$ & $26.13(4.4)$ & $-1.75(2.9)$ & $0.88(2.7)$ \\
\hline \multirow[t]{2}{*}{ APOE4 - } & Placebo & $6.00(3.6)$ & $23.08(3.6)$ & $3.00(2.6)$ & $4.24(2.6)$ \\
\hline & Tamoxifen & $5.5 \mid(3.9)$ & 20.91 (3.9) & $7.12(2.5)$ & $2.29(2.4)$ \\
\hline \multirow[t]{2}{*}{ APOE4 + } & Placebo & $-2.27(0.9)$ & $-4.38(0.9)$ & $-1.00(1.0)$ & $-0.43(1.04)$ \\
\hline & Tamoxifen & $-2.00(0.8)$ & $-5.38(0.9)$ & $-0.38(1.0)$ & $0.38(1.0)$ \\
\hline \multirow[t]{2}{*}{ APOE4 - } & Placebo & $-2.08(0.7)$ & $-4.17(0.7)$ & $-1.50(0.8)$ & $-2.00(0.83)$ \\
\hline & Tamoxifen & $-0.78(0.8)$ & $-2.68(0.8)$ & $0(0.9)$ & $-0.30(0.9)$ \\
\hline POE4 + & Placebo & $-2.5 \mid(1.0)$ & $-4.63(0.9)$ & $-1.61(0.9)$ & $-0.76(0.9)$ \\
\hline
\end{tabular}$$
-11.68(4.5)
$$$$
\text { APOE4 - Placebo }
$$$$
\text { Tamoxifen }
$$
correct)$$
-32.13(4.2)
$$$$
-8.00(4.2)
$$$$
-28.75(4.2)
$$

$1.34(2.6)$
$-0.50(2.0)$
$0.15(2.0)$
$-1.11(1.7)$

$-3.19(3.7)$

$-1.25(3.0)$

$-6.58(3.0)$

$-1.51(2.6)$

$-1.70(4.62)$

$-5.14(3.7)$

$-21.54(3.7)$

$-6.58(3.8)$

$-6.07(3.9)$

$-6.79(6.2)$

$-1.70(4.62)$

(4.4)

$-0.97(3.9)$

$14(3.3)$

$.88(2.7)$

$24(2.6)$

$38(1.0)$

$-0.30(0.9)$

$-0.76(0.9)$ 
Table 1 (Continued)

\begin{tabular}{|c|c|c|c|c|c|c|c|c|}
\hline $\begin{array}{l}\text { Cognitive } \\
\text { construct }\end{array}$ & Task & Dependent variable & Genotype & Treatment & $\begin{array}{c}2.5 \mu \mathrm{g} / \mathrm{kg} \\
\text { SCOP }\end{array}$ & $\begin{array}{c}5.0 \mu \mathrm{g} / \mathrm{kg} \\
\text { SCOP }\end{array}$ & $10 \mathrm{mg}$ MECA & $20 \mathrm{mg}$ MECA \\
\hline & & & & Tamoxifen & $-1.50(0.9)$ & $-4.12(0.9)$ & $-0.25(0.9)$ & $0.50(0.9)$ \\
\hline & & & & Tamoxifen & $-0.92(0.8)$ & $-3.4 \mid(0.8)$ & $-0.32(0.8)$ & $0.18(0.8)$ \\
\hline \multicolumn{9}{|c|}{$\begin{array}{l}\text { Spatial navigation/ } \\
\text { memory }\end{array}$} \\
\hline & & \multirow[t]{4}{*}{ Platform latency hidden (s) } & \multirow[t]{2}{*}{ APOE4 + } & Placebo & $-0.52(3.7)$ & $4.08(5.8)$ & $5.88(4.3)$ & $3.28(4.3)$ \\
\hline & & & & Tamoxifen & $-4.35(5.4)$ & $5.08(4.2)$ & $-12.09(4.1)$ & I. $17(4.2)$ \\
\hline & & & \multirow[t]{2}{*}{ APOE4 - } & Placebo & $2.81(3.0)$ & $5.80(4.7)$ & $4.86(3.3)$ & $-0.79(3.3)$ \\
\hline & & & & Tamoxifen & $1.16(4.4)$ & $7.16(3.4)$ & $6.05(3.3)$ & 3.61 (3.3) \\
\hline & & \multirow[t]{6}{*}{$\begin{array}{l}\text { Distance to platform } \\
\text { hidden }\end{array}$} & APOE4 + & Placebo & $471.32(479.4)$ & $223.04(497.4)$ & $359.03(353.4)$ & I $46.73(353.4)$ \\
\hline & & & APOE4 - & Tamoxifen & $14.19(495.6)$ & $755.70(486.9)$ & $589.83(259.3)$ & 375.41 (270.8) \\
\hline & & & \multirow{2}{*}{ APOE4 + } & Placebo & $-231.52(295.6)$ & $-474.76(269.5)$ & $-271.80(353.0)$ & $-183.76(37 \mid .6)$ \\
\hline & & & & Tamoxifen & $104.55(\mid 60.8)$ & $138.9(247.0)$ & $304.47(216.5)$ & $294.85(183.8)$ \\
\hline & & & \multirow[t]{2}{*}{ APOE4 - } & Placebo & $-293.66(232.3)$ & $-212.21(220.0)$ & $-213.21(251.1)$ & $-75.60(268.0)$ \\
\hline & & & & Tamoxifen & $281.84(\mid 31.3)$ & $383.92(201.6)$ & | $46.43($ ( 65.4$)$ & $250.74(140.4)$ \\
\hline & & \multirow[t]{4}{*}{ Platform latency visible (s) } & \multirow[t]{2}{*}{ APOE4 + } & Placebo & $0.50(1.2)$ & $0.78(1.1)$ & $-0.44(0.9)$ & $-0.52(0.9)$ \\
\hline & & & & Tamoxifen & $0.16(1.1)$ & $2.50(1.1)$ & $1.86(0.8)$ & $0.32(0.8)$ \\
\hline & & & \multirow[t]{2}{*}{ APOE4 - } & Placebo & $-0.66(0.9)$ & $-0.28(1.0)$ & $-0.25(0.7)$ & $-0.80(0.7)$ \\
\hline & & & & Tamoxifen & $0.05(0.9)$ & $-0.58(0.9)$ & $0.34(0.6)$ & $1.16(0.6)$ \\
\hline
\end{tabular}

Numbers represent least squared means (standard errors) for difference scores (challenge drug minus placebo). See text for challenge drug effects. Cognitive tasks are choice reaction time (CRT) test, digit span (DS), fluency test (FT), Buschke selective reminding test (SRT), virtual Morris water maze (MWM).

high-dose SCOP increased latency more than low-dose SCOP. For travel distance in the platform hidden blocks, there was trend towards a TMX treatment by SCOP dose interaction $(F(1,18)=3.26, p=0.09)$, and the pattern of means indicated that there was a reduction in distance in TMX treatment compared with placebo after SCOP challenge. On the distance traveled during the probe trial, there was a main effect of TMX treatment $(F(1,18)=6.02$, $p=0.02$ ) that showed distance traveled increased after TMX treatment compared with placebo. For the visible platform trials, there was a main effect of treatment $(F(1,15)=8.72$, $p=0.01$ ), with TMX treatment associated with an increase in latency compared with placebo.

The effects of MECA and interactions with TMX were more robust. There was an interaction of TMX treatment and MECA dose on latency to find the hidden platform $(F(1,17)=7.57, p=0.02)$ as well as an interaction of TMX treatment and block on platform latency $(F(3,49)=4.08$, $p=0.01$ ) (Figure 4). After TMX treatment, women had reduced latency to find the hidden platform on blocks $2(t(41)=2.11, p=0.04)$ and $3(t(41)=2.16, p<0.04)$. There was also a APOE4 genotype by TMX treatment interaction on latency $(F(1,17)=13.23, p<0.01)$ with post hoc $t$-tests showing that TMX treatment reduced latency to find the hidden platform for the APO $\varepsilon 4+$ women compared with placebo $(t(61)=3.40, p=0.001)$, whereas there was no significant effect of TMX treatment for APOE $\varepsilon 4-$ women $(t(60)=1.76, p=0.08)$ (Figure 4). Distance traveled showed a significant benefit (reduction) of TMX treatment, with a significant TMX treatment by block interaction $(F(3,49)=3.9, p=0.01)$. TMX reduced the distance traveled relative to placebo treatment $(t(38)=2.12, p=0.04)$ on the third block. There was also a APOE $\varepsilon 4$ genotype by TMX treatment interaction for the distance traveled $(F(1,17)=18.53, p<0.01)$, with TMX significantly reducing the distance traveled on the hidden platform trials in APOE $\varepsilon 4+$ women $(t(62)=3.04, p=0.003)$. Examination of the probe trial showed that there was a trend for TMX to reduce 

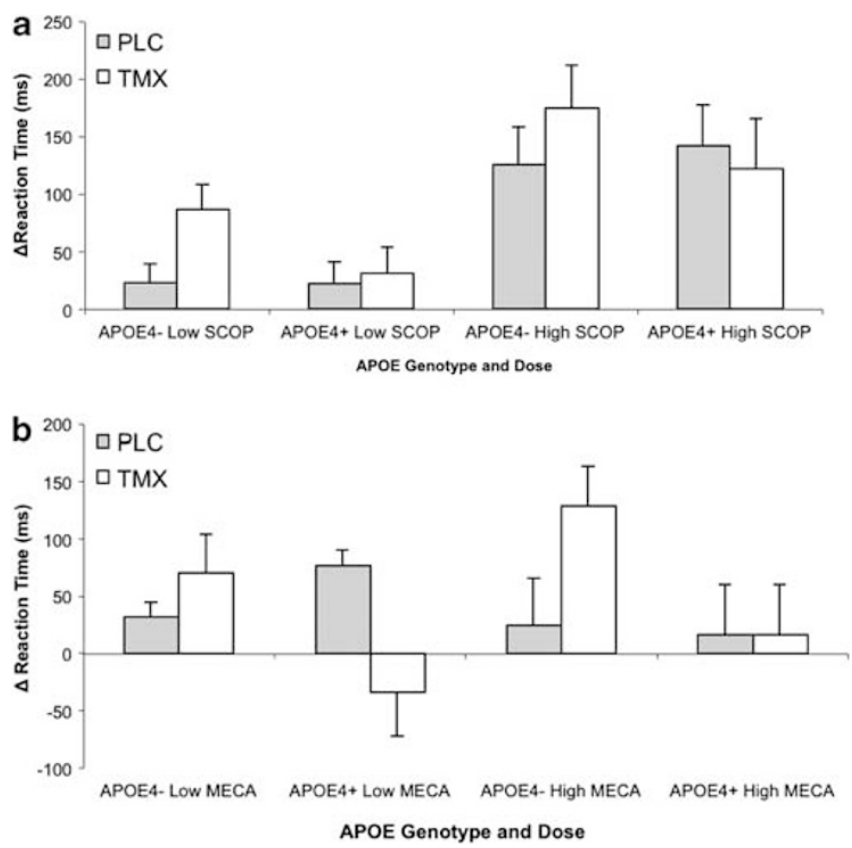

Figure 2 Choice reaction time (CRT), total. Scores represent change from placebo challenge in median reaction time (ms \pm SEM). Plotted by genotype (APO $\varepsilon 4+/-$ ) and drug dose (low, high). (a) SCOP: significant main effect of TMX treatment $(p<0.00 \mathrm{I})$. (b) MECA: significant treatment by challenge interaction $(p=0.05)$.

the distance traveled $(F(1,17)=3.52, p=0.08)$ after MECA challenge. There were no MECA or TMX effects on visible platform measures, but there was trend for a main effect of APOE4 genotype $(F(1,17)=3.52, p=0.08)$ with APOE $\varepsilon 4+$ participants having numerically greater latency times.

\section{Behavioral Measures}

There were statistically significant, but clinically minor, effects of SCOP and MECA on behavioral, mood, and physical symptoms that can be summarized as expected effects from the anticholinergic drugs similar to those seen in prior studies (eg, Dumas et al, 2006).

TMX effects were limited. There were significant main effects of TMX on reducing the Physical Symptom Checklist score $(F(1,19)=11.05, p=0.0036)$ and the Stanford Sleepiness Scale Score $(F(1,18)=8.48, p=0.009)$ after SCOP administration. TMX reduced the effects of the anticholinergic challenge drugs on Tension ratings after SCOP $(F(1,21)=4.47, p=0.047)$ and Irritability $(F(1,15)=5.04$, $p=0.04)$ after MECA, especially at low dose. There were no significant effects of TMX treatment on any of the mood measures (BDI, BAI, and POMS) (largest $t(20)=1.75$, smallest $p=0.08$ ). Thus, TMX treatment affected very few of the subjective or objective ratings and changes to these ratings were quantitatively minor.

\section{Vital Signs}

As with the behavioral measures, effects on vital signs were similar to that in prior studies. MECA produced a significant decrease in systolic blood pressure
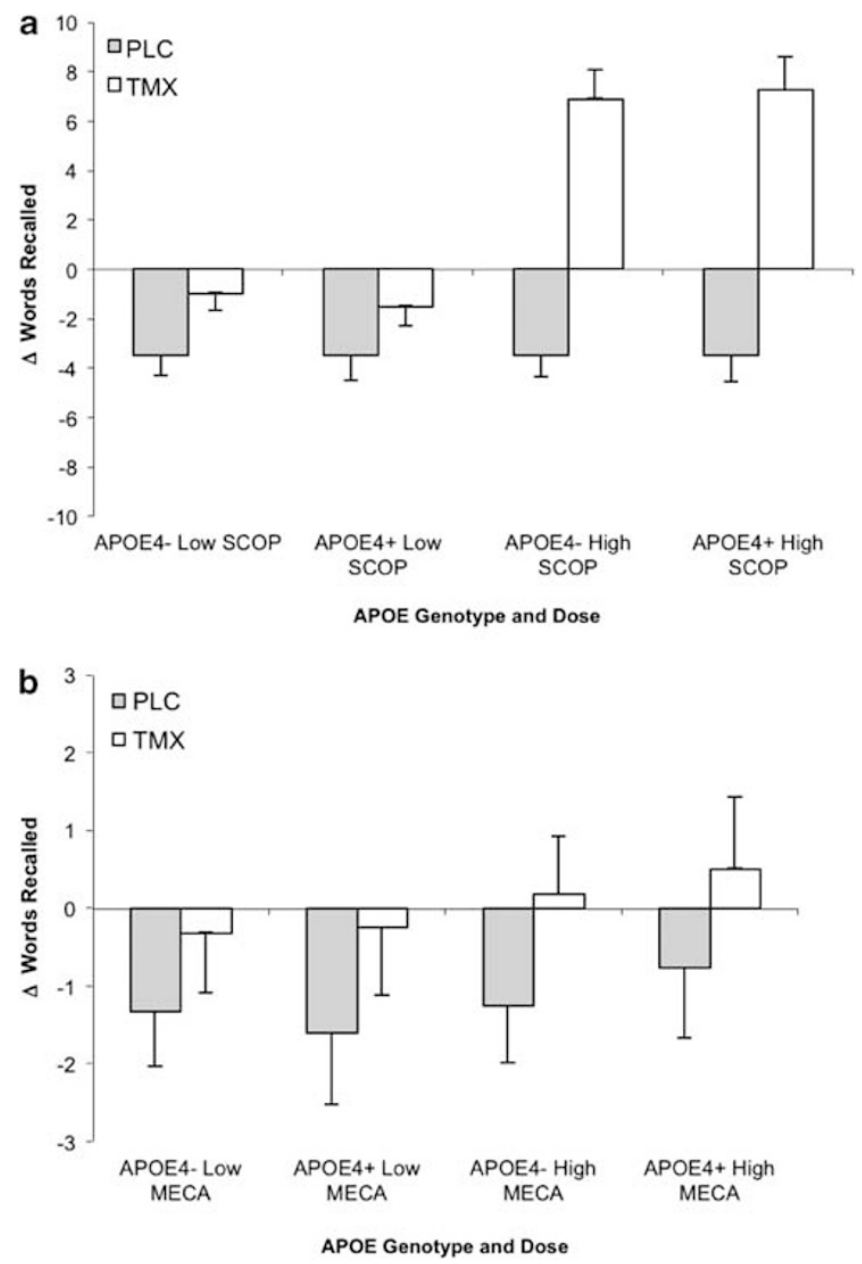

Figure 3 Selective reminding task. Scores represent change from placebo challenge in total delayed recall (words \pm SEM). Plotted by genotype (APO $\varepsilon 4+1-$ ) and drug dose (low, high). (a) SCOP: significant main effect of TMX treatment $(p=0.04)$. (b) MECA: trend for treatment by challenge interaction $(p=0.06)$.

$(F(1,20)=6.98, p=0.02)$ and increase in pupil diameter $(F(1,20)=17.56, p<0.001)$. The only effect of TMX was to reduce the effect of SCOP on oral temperature $(F(1$, 20) $=4.33, p=0.051$ ).

\section{DISCUSSION}

The results of this study showed that TMX administration reduced anticholinergic effects on cognitive performance in most but not all domains. TMX treatment reduced the negative effects of cholinergic antagonists on verbal episodic memory, with reduction of the effects of SCOP on recall consistency and effects of SCOP and MECA on delayed recall during TMX treatment. This was consistent with an estrogen-like effect similar to our prior study that showed that E2 treatment enhanced verbal episodic memory performance after cholinergic challenge, particularly in younger postmenopausal women (Dumas et al, 2008).

A second important finding was the effect of TMX treatment on spatial learning/spatial navigation in the 

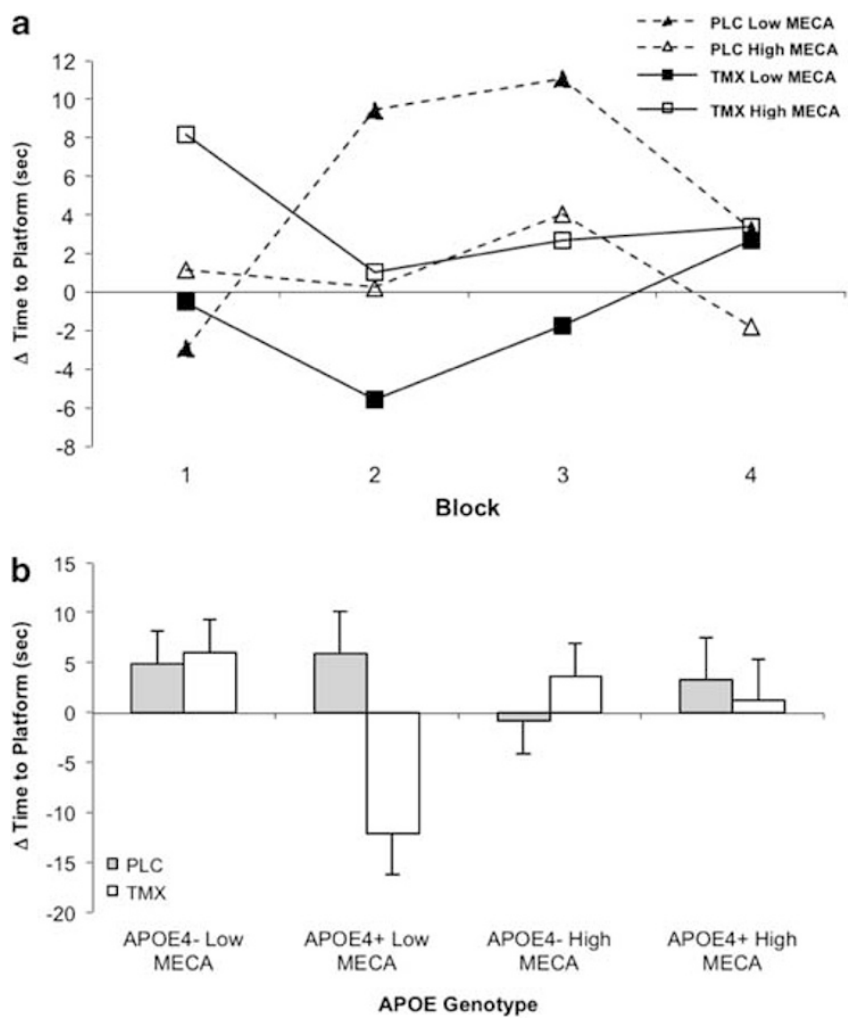

Figure 4 Virtual Morris water maze task. (a) MECA: scores represent change from placebo challenge in latency to find hidden platform (s) across blocks (four trials per block) by dose of challenge agent. Significant treatment*challenge interaction $(p=0.02)$. Low $(10 \mathrm{mg})$ and high $(20 \mathrm{mg})$ represent acute doses of mecamylamine. PLC and TMX represent chronic treatment with placebo or tamoxifen. (b) Mean platform latency ( $s \pm$ SEM) by genotype (APO $\varepsilon 4+1-$ ) and dose for MECA challenge collapsed across blocks. Significant treatment by genotype effect $(p<0.0 \mathrm{I})$.

VMWM task. Both anticholinergic challenge drugs impaired spatial navigation performance and TMX treatment was associated with a reduction of these effects, particularly after antinicotinic challenge. TMX treatment was associated with a reduction of the cholinergic blockade effects on the learning phase of the task, with a reduction in hidden platform latency. This occurred despite evidence for altered psychomotor function as TMX treatment was associated with longer travel times to the visible platform.

While the exact reasons for improvement in the performance of spatial navigation task cannot be ascertained from these results alone, proper performance of this task requires intact hippocampal function (Astur et al, 2002); thus, these results suggest that TMX enhances hippocampal function directly and/or enhances cholinergic tone and modulation of hippocampal activity. Positive effects on hippocampal function are also supported by the effects of TMX treatment on the relative protection of verbal episodic memory function from cholinergic blockade, which is also dependent on intact hippocampal functioning.

Treatment with TMX treatment tended to decrease the effects of the antinicotinic agent mecamylamine, but increased the effects of antimuscarinic scopolamine in the CRT task. We have previously shown (Dumas et al, 2006) that estradiol (E2) treatment reduced the effect of both anticholinergic challenge drugs on CRT performance. TMX also tended to increase latency to the visible platform in the VMWM task despite improving latency to find the hidden platform after anticholinergic challenge. Thus, the results seen on some psychomotor measures suggest an antiestrogen-like effect of TMX on psychomotor speed, particularly after scopolamine.

The potential reasons as to why TMX would have E2 agonist-like effects particularly on hippocampally mediated tasks and mixed agonist-antagonist-like effects on some attention/RT tasks cannot be completely ascertained from this study. However, TMX and E2 have different effects at different estrogen receptors, and differentially regulate target genes (Kian Tee et al, 2004); thus, TMX may have agonist-like effects on some brain systems, but not others. The relative balance of estrogen agonist $v s$ antagonist-like effects of tamoxifen may differ in different areas of the brain because of differences in estrogen receptor distribution.

Agonist stimulation of ERs appears to have significant effects on cholinergic function and subsequent cognitive performance, particularly in tasks that require an intact hippocampus (Gibbs, 2010). In rodent models, ovariectomy with loss of E2 produces poor performance on learning and memory tasks, and this decline in performance parallels a decline in cholinergic activity and ChAT levels in several brain regions, whereas E2 replacement prevents this decline (Singh et al, 1994). E2 administration counteracts the negative learning effects of the cholinergic antagonist SCOP on alternation learning (Dohanich et al, 1994), and E2 replacement in ovariectomized rats enhances the acquisition of spatial memory tasks, and partially or completely blunted the effects of SCOP (Gibbs, 1999; Tanabe et al, 2004) as well as improving working memory and preventing amnestic effects (Fader et al, 1999). When cholinergic systems are experimentally destroyed or blocked, E2 administration was ineffective in enhancing learning (Daniel et al, 2005; Gibbs, 2001), suggesting the cholinergic systems were critical for E2 to have cognitively enhancing effects. Long-term loss of estrogen function produced a decrease in the functional status of basal forebrain cholinergic neurons, particularly projecting to the hippocampus and cortex (Gibbs, 1998), and treatment with E2 restored ChAT mRNA in the medial septum and trkA mRNA in the nucleus basalis (Yamamoto et al, 2007). In humans, greater muscarinic cholinergic receptor density in hippocampus and frontal cortex as well as some cortical areas was found in HT users compared with nonusers (Norbury et al, 2007). Estrogenic stimulation also appears to alter hippocampal structure and function (Bi et al, 2001; Fester et al, 2006; Woolley and McEwen, 1993) including increasing the density of dendritic spines on CA1 pyramidal neurons (Yankova et al, 2001). Studies suggested that ERs were specifically localized beyond the cytoplasm in neurons in hippocampus and cortex (Brann et al, 2007), including plasma membrane, dendritic shafts, and spines. This extranuclear localization supports the idea that estrogenic stimulation may have local effects on hippocampal and cortical processes to regulate synaptic plasticity.

In this study, TMX appeared to be acting as an E2 agonist on hippocampally mediated tasks. This is not without precedent. Several studies have shown that TMX acted as an ER agonist in the absence of E2 and furthermore this action 
was regionally specific with agonist-like effects in some brain areas and antagonist effects in others (GonzalezBurgos et al, 2012). TMX increased hippocampal (GonzalezBurgos et al, 2012; Silva et al, 2000) and prefrontal (Velazquez-Zamora et al, 2012) spine density, and mimicked estrogen effects on NMDA and AMPA receptors in the hippocampus and striatum (Cyr et al, 2001a; Cyr et al, 2001b; Cyr et al, 2001c). TMX treatment was also associated with estrogen-like effects on markers of neuroprotection in rat hippocampus Sharma and Mehra, 2008. TMX shows effects similar to E2 on AMPA receptor expression in certain brain regions (Cyr et al, 2001b) and also acts to preserve hippocampal NMDA receptor function similar to E2 (Cyr et al, 2001a).

If the actions of TMX on cholinergic basal forebrain neurons are mediated in part through actions at classic ERs, it is more likely that this takes place through interactions with $\mathrm{ER} \alpha$ as these neurons do not appear to express $\mathrm{ER} \beta$ (Shughrue et al, 2000), and TMX may be a complete antagonist at $\operatorname{ER} \beta$ (McInerney et al, 1998), although $\operatorname{ER} \beta$ has been shown to be more important for regulating synaptic plasticity and hippocampus-dependent memory tasks, at least in rodents (Liu et al, 2008). TMX may also be functioning in this study through interactions with GPR30, a novel G-protein-coupled estrogen receptor that is widely expressed in the brain. GPR30 appears to be responsible for the rapid effects of estrogen (Hazell et al, 2009), and this receptor appears to be expressed on cholinergic neurons of the basal forebrain and other areas of the brain involved in cognitive performance (Hammond and Gibbs, 2011). TMX also interacts with this receptor as an agonist (Ignatov et al, 2010; Maggiolini and Picard, 2010).

Several investigators have shown results consistent with neuroprotective effects of TMX in experimental models such as reductions in MPP + -induced hydroxy radical generation (Obata and Kubota, 2001), increasing the levels of superoxide dismutase (Wakade et al, 2008), reducing mitochondrial injury produced by oxidative stress (Moreira et al, 2005), and protecting neurons from kainic acid lesions (Ciriza et al, 2004). Neuroprotective effects of TMX were suggested in a unique study by Ernst et al (2002) in which women treated with TMX showed similar magnetic resonance spectroscopy-measured levels of myoinositol compared with E2-treated women, and less than nontreated women, suggesting less glial activity. By contrast, a study by Eberling et al (2004) showed that women with breast cancer who took TMX had widespread areas of reduced brain metabolism and reduced hippocampal volume and semantic memory. However, the effects of breast cancer and cancer treatment could not be disentangled from the effects of TMX in this study.

Dhandapani and Brann (2003) have suggested that SERMs such as TMX may exert neuroprotection through genomic estrogen receptor-mediated pathways, non-genomic signaling pathways, and antioxidant free-radical scavenging. In studies comparing TMX effects on bone density in intact and ovariectomized rats ( $\mathrm{Li}$ et al, 1996) and premenopausal breast cancer patients who continued to menstruate following treatment or experienced chemotherapy-induced amenorrhea (Vehmanen et al, 2006), results suggest that TMX has estrogen-like effects only in the absence of endogenous estrogen, and has no effect in its presence.
In addition to the study by Eberling et al (2004) cited above, one large study examined 710 patients treated with TMX post breast cancer chemotherapy (Paganini-Hill and Clark, 2000) and found that current use of TMX was associated with greater likelihood of complaints regarding memory problems than never users or past users. A recent study of 77 patients treated with TMX and/or aromatase inhibitors showed that endocrine therapy was related to the perception of attentional and overall cognitive functioning, although no relationship was found between endocrine treatment and objective cognitive measures (Breckenridge et al, 2012). By contrast, Breuer and Anderson (2000) examined the nursing home records of 1385 women who had received TMX treatment compared with otherwise similar women who have not. Women receiving TMX were less likely to have a diagnosis of Alzheimer's disease $(\mathrm{OR}=0.674)$ and were significantly more independent in ADLs than in matched controls.

Menopausal status may be a crucial factor in determining whether TMX is beneficial or harmful for cognition, presumably dictating whether TMX acts primarily as an agonist or an antagonist of CNS ERs. In studies of premenopausal breast cancer patients who were not receiving chemotherapy, and had no change in their estrogen status, TMX treatment was associated with worse performance on tasks of visual memory, verbal fluency, visuo-spatial attention, and immediate verbal recall Palmer et al (2008). However, a large prevention study of postmenopausal women, who had a precursor breast cancer condition, revealed that TMX treatment did not impair similar tasks including verbal fluency, spatial attention and ability, verbal memory, and working memory (Legault et al, 2009).

The effect of APOE genotype on the cognitive response to TMX treatment and the interaction with cholinergic antagonist challenge agents is intriguing. The salutary effects of TMX on cholinergic-mediated cognitive performance seemed to be most robust in the APOE $\varepsilon 4+$ subjects. While this study was not designed or powered to test the primary hypothesis of differences by APOE genotype, the APOE $\& 4$ genotype is considered to be a major risk factor for Alzheimer's disease, and the presence of even a single $\varepsilon 4$ allele has been shown to be a risk factor for increased cognitive dysfunction following cancer chemotherapy (Ahles et al, 2003). Wang et al (2006) showed that activation of $\mathrm{ER} \alpha$ upregulated APOE mRNA and protein expression whereas ER $\beta$ downregulated both those measures in vitro, suggesting that beneficial effects of TMX may be due to selective effects at one of the two ER subtypes. APOE $\& 4$ genotype appears to be related to cholinergic dysfunction, and APOE \&4 allele copy number shows an inverse relationship with brain ChAT activity and nicotinic receptor binding in Alzheimer's disease subjects in the hippocampus and temporal lobe (Poirier et al, 1995). Whether this would be seen in the otherwise normal individuals studied here is unclear. It is possible that the estrogen-like activity of TMX would have a greater impact on basal forebrain cholinergic systems in subjects that already have early cholinergic dysfunction due to the presence of the APOE $\& 4$ genotype; thus, any potential compensatory cognitive effect would be greater (Dumas and Newhouse, 2011). Whether TMX has promise as a prophylactic treatment to improve cognitive 
function in APO $\varepsilon 4+$ individuals would require a prospective study design, but the positive effects seen in APOE $\varepsilon 4+$ individuals certainly suggest that further studies of the effects of SERM on cognition should take this genotype into account.

Limitations of this study include the relatively small sample (but with an intensive, within-subjects design) and the broad age range of the participants. As others have suggested (Sherwin, 2007) and we have experimentally verified (Dumas et al, 2008), positive effects on cognitive function of E2 may be restricted to early postmenopausal women rather than to women $\geqslant 20$ years postmenopause. We preliminarily examined the SRT data in this study utilizing a median split by age and found that younger women (mean age 53) were more responsive to TMX in terms of reducing the effects of anticholinergic challenge on verbal recall than older women (mean age 66). However, validation of this effect will require further investigation. Participants in this study were healthy normals, thus how these findings might predict effects in breast cancer patients with prior chemotherapy unclear. There may be significant differences in the longterm effects of TMX depending on whether a woman is pre- or postmenopausal (Powles et al, 1996). How this model relates to the long-term effects of TMX treatment that might be typically seen with breast cancer treatment (eg, 510 years) is unclear. There are some suggestions that chronic treatment with E2 or similar agents can enhance markers of cholinergic and neuronal functioning in some animal model systems (Hao et al, 2006; Tinkler and Voytko, 2005), but not others (Gibbs, 2000). These results provide further validation regarding our previous findings of estrogen-related stimulation on cholinergic tone, and support the hypothesis that stimulation of estrogen receptors may affect cognitive functioning through cholinergic mechanisms. This work further suggests that careful design and utilization of SERMs may have long-term benefits on brain function without some of the liabilities of E2 (Brinton, 2002). Future work should include studies of how TMX alters task-related functional brain activity and functional connectivity related to cholinergic function. Additionally, examining the effects of chronic TMX in individuals at high-risk $v s$ low-risk for late-life cognitive dysfunction may be valuable in determining whether TMX has potential value for long-term prophylaxis to preserve late-life cognitive function.

\section{FUNDING AND DISCLOSURE}

The authors declare no conflict of interest.

\section{ACKNOWLEDGEMENTS}

We wish to acknowledge the invaluable contributions of Dr Emily Coderre, Dr Jessica Salerno, Christy Edgren, the nursing staff of the Clinical Research Center at the University of Vermont, and our research volunteers for their dedication to clinical research. This work was supported by NIA R01 AG021476, NIA K01 030380, and NCRR M01-00109.

\section{REFERENCES}

Ahles TA, Saykin AJ, Noll WW, Furstenberg CT, Guerin S, Cole B et al (2003). The relationship of APOE genotype to neuropsychological performance in long-term cancer survivors treated with standard dose chemotherapy. Psycho-Oncology 12: 612-619.

Astur RS, Ortiz ML, Sutherland RJ (1998). A characterization of performance by men and women in a virtual Morris water task: a large and reliable sex difference. Behav Brain Res 93: 185-190.

Astur RS, Taylor LB, Mamelak AN, Philpott L, Sutherland RJ (2002). Humans with hippocampus damage display severe spatial memory impairments in a virtual Morris water task. Behav Brain Res 132: 77-84.

Beck AT, Ward CH, Mendelson M, Mock J, Erbaugh J (1961). An inventory for measuring depression. Arch Gen Psychiatr 4: 53-63.

Bi R, Foy MR, Vouimba RM, Thompson RF, Baudry M (2001). Cyclic changes in estradiol regulate synaptic plasticity through the MAP kinase pathway. Proc Natl Acad Sci USA 98: 13391-13395.

Brann DW, Dhandapani K, Wakade C, Mahesh VB, Khan MM (2007). Neurotrophic and neuroprotective actions of estrogen: basic mechanisms and clinical implications. Steroids 72: 381-405.

Breckenridge LM, Bruns GL, Todd BL, Feuerstein M (2012). Cognitive limitations associated with tamoxifen and aromatase inhibitors in employed breast cancer survivors. Psycho-Oncology 21: 43-53.

Bretsky P, Guralnik JM, Launer L, Albert M, Seeman TE (2003). The role of APOE- $\varepsilon 4$ in longitudinal cognitive decline: MacArthur studies of successful aging. Neurology 60: 1077-1081.

Breuer B, Anderson R (2000). The relationship of tamoxifen with dementia, depression, and dependence in activities of daily living in elderly nursing home residents. Women Health 31: 71-86.

Brinton RD (2002). Selective estrogen receptor modulators (SERM) for the brain: recent advances and remaining challenges for developing a NeuroSERM (TM). Drug Develop Res 56: 380-392.

Buschke H (1973). Selective reminding for analysis of memory and learning. J Verbal Learn Verbal Behav 12: 543-550.

Chen D, Chun-Fu W, Shi B, Xu Y (2002). Tamoxifen and toremifene impair retrieval, but not acquisition, of spatial information processing in mice. Pharmacol Biochem Behav 72: 417-421.

Ciriza I, Carrero P, Azcoitia I, Lundeen SG, Garcia-Segura LM (2004). Selective estrogen receptor modulators protect hippocampal neurons from kainic acid excitotoxicity: differences with the effect of estradiol. J Neurobiol 61: 209-221.

Coker LH, Espeland MA, Rapp SR, Legault C, Resnick SM, Hogan P et al (2010). Postmenopausal hormone therapy and cognitive outcomes: the Women's Health Initiative Memory Study (WHIMS). J Steroid Biochem Mol Biol 118: 304-310.

Collaborative GoHFiBC (1997). Breast cancer and hormone replacement-therapy: collaborative reanalysis of data from 51 epidemiologic studies of 52,705 women with breast cancers and 108,411 women without breast cancer. Lancet 350: 1047-1059.

Cyr M, Ghribi O, Thibault C, Morissette M, Landry M, Di Paolo T (2001a). Ovarian steroids and selective estrogen receptor modulators activity on rat brain NMDA and AMPA receptors. Brain Res Rev 37: 153-161.

Cyr M, Morissette M, Landry M, Di Paolo T (2001b). Estrogenic activity of tamoxifen and raloxifene on rat brain AMPA receptors. Neuroreport 12: 535-539.

Cyr M, Thibault C, Morissette M, Landry M, Di Paolo T (2001c). Estrogen-like activity of tamoxifen and raloxifene on NMDA receptor binding and expression of its subunits in rat brain. Neuropsychopharmacology 25: 242-257.

Daniel JM, Hulst JL, Lee CD (2005). Role of hippocampal M2 muscarinic receptors in the estrogen-induced enhancement of working memory. Neuroscience 132: 57-64. 
Dhandapani KM, Brann DW (2003). Neuroprotective effects of estrogen and tamoxifen in vitro. Endocrine 21: 59-66.

Dohanich GP, Fader AJ, Javorsky DJ (1994). Estrogen and estrogen-progesterone treatments counteract the effect of scopolamine on reinforced T-maze alternation in female rats. Behav Neurosci 108: 988-992.

Dumas J, Hancur-Bucci C, Naylor M, Sites C, Newhouse P (2008). Estradiol interacts with the cholinergic system to affect verbal memory in postmenopausal women: evidence for the critical period hypothesis. Hormone Behav 53: 159-169.

Dumas JA, Hancur-Bucci C, Naylor M, Sites C, Newhouse PA (2006). Estrogen treatment effects on anticholinergic-induced cognitive dysfunction in normal post-menopausal women. Neuropsychopharmacology 31: 2065-2078.

Dumas JA, Kutz AM, Naylor MR, Johnson JV, Newhouse PA (2012). Estradiol reversal of anticholinergic-related brain activation in postmenopausal women. Neuroimage 60: 1394-1403.

Dumas JA, Newhouse PA (2011). The cholinergic hypothesis of cognitive aging revisited again: Cholinergic functional compensation. Pharmacol Biochem Behav 99: 254-261.

Eberling JL, Wu C, Tong-Turnbeaugh R, Jagust WJ (2004). Estrogen- and tamoxifen-associated effects on brain structure and function. Neuroimage 21: 364-371.

Ernst T, Chang L, Cooray D, Salvador C, Jovicich J, Walot I et al (2002). The effects of tamoxifen and estrogen on brain metabolism in elderly women. J Natl Cancer Inst 94: 592-597.

Esmaeili B, Basseda Z, Gholizadeh S, Javadi Paydar M, Dehpour AR (2009). Tamoxifen disrupts consolidation and retrieval of morphine-associated contextual memory in male mice: interaction with estradiol. Psychopharmacology (Berl) 204: 191-201.

Ewertz M, Mellemkjaer L, Poulsen AH, Friis S, Sorensen HT, Pedersen L et al (2005). Hormone use for menopausal symptoms and risk of breast cancer. A Danish cohort study. Br J Cancer 92: 1293-1297.

Fader AJ, Johnson PEM, Dohanich GP (1999). Estrogen improves working but not reference memory and prevents amnestic effects of scopolamine on a radial-arm maze. Pharmacol Biochem Behav 62: 711-717.

Falleti MG, Sanfilippo A, Maruff P, Weih L, Phillips KA (2005). The nature and severity of cognitive impairment associated with adjuvant chemotherapy in women with breast cancer: a metaanalysis of the current literature. Brain Cogn 59: 60-70.

Fester L, Ribeiro-Gouveia V, Prange-Kiel J, von Schassen C, Bottner M, Jarry H et al (2006). Proliferation and apoptosis of hippocampal granule cells require local oestrogen synthesis. J Neurochem 97: 1136-1144.

First MB, R.L. S, Gibbon M, Williams JBW (2001). Structured Clinical Interview for DSM-IV-TR Axis I Disorders-Patient Edition, SCID-I/P, 2/2001 ednAmerican Psychiatric Press Inc: Washington, DC, USA.

Gibbs RB (1998). Impairment of basal forebrain cholinergic neurons associated with aging and long-term loss of ovarian function. Exp Neurol 151: 289-302.

Gibbs RB (1999). Estrogen replacement enhances acquisition of a spatial memory task and reduces deficits associated with hippocampal muscarinic receptor inhibition. Hormone Behav 36: $222-233$.

Gibbs RB (2000). Effects of gonadal hormone replacement on measures of basal forebrain cholinergic function. Neuroscience 101: 931-938.

Gibbs RB (2001). Estrogen enhancement of learning requires intact basal forebrain cholinergic neutrons. Soci Neurosci Abstr 31: 312.

Gibbs RB (2010). Estrogen therapy and cognition: a review of the cholinergic hypothesis. Endocrine Rev 31: 224-253.

Gonzalez-Burgos I, Rivera-Cervantes MC, Velazquez-Zamora DA, Feria-Velasco A, Garcia-Segura LM (2012). Selective estrogen receptor modulators regulate dendritic spine plasticity in the hippocampus of male rats. Neural Plast 2012: 309494.
Hammond R, Gibbs RB (2011). GPR30 is positioned to mediate estrogen effects on basal forebrain cholinergic neurons and cognitive performance. Brain Res 1379: 53-60.

Hao J, Rapp PR, Leffler AE, Leffler SR, Janssen WGM, Lou W et al (2006). Estrogen alters spine number and morphology in prefrontal cortex of aged female rhesus monkeys. If Neurosci 26: 2571-2578.

Hazell GGJ, Yao ST, Roper JA, Prossnitz ER, O’Carroll A-M, Lolait SJ (2009). Localisation of GPR30, a novel G proteincoupled oestrogen receptor, suggests multiple functions in rodent brain and peripheral tissues. J Endocrinol 202: 223-236.

Hindmarch I (1984). Psychological performance models as indicators of the effects of hypnotic drugs on sleep. Psychopharmacology S1: 58-68.

Hoddes ElZ V, Smythe H, Phillips R, Dement W (1973). Quantification of sleepiness: a new approach. Psychophysiology 10: 431-436.

Hulley S, Grady D (2004). The WHI estrogen-alone trial-do things look any better? J Am Med Assocn 291: 1769-1771.

Ignatov A, Ignatov T, Roessner A, Costa S, Kalinski T (2010). Role of GPR30 in the mechanisms of tamoxifen resistance in breast cancer MCF-7 cells. Breast Cancer Res Treat 123: 87-96.

Kang JH, Grodstein F (2012). Postmenopausal hormone therapy, timing of initiation, APOE and cognitive decline. Neurobiol Aging 33: 1129-1137.

Kian Tee M, Rogatsky I, Tzagarakis-Foster C, Cvoro A, An J, Christy RJ et al (2004). Estradiol and selective estrogen receptor modulators differentially regulate target genes with estrogen receptors $\alpha$ and $\beta$. Mol Biol Cell 15: 1262-1272.

Kristensen B, Ejlertsen B, Dalgaard P, Larsen L, Holmegaard SN, Transbol I et al (1994). Tamoxifen and bone metabolism in postmenopausal low-risk breast cancer patients: a randomized study. J Clin Oncol 12: 992-997.

Lagunas N, Calmarza-Font I, Grassi D, Garcia-Segura LM (2011). Estrogen receptor ligands counteract cognitive deficits caused by androgen deprivation in male rats. Hormone Behav 59: 581-584.

Legault C, Maki PM, Resnick SM, Coker L, Hogan P, Bevers TB et al (2009). Effects of tamoxifen and raloxifene on memory and other cognitive abilities: cognition in the study of tamoxifen and raloxifene. J Clin Oncol 27: 5144-5152.

Li X, Takahashi M, Kushida K, Koyama S, Hoshino H, Kawana K et al (1996). The effect of tamoxifen on bone metabolism and skeletal growth is different in ovariectomized and intact rats. Calc Tissue Int 59: 271-276.

Liu F, Day M, Muniz LC, Bitran D, Arias R, Revilla-Sanchez R et al (2008). Activation of estrogen receptor-[beta] regulates hippocampal synaptic plasticity and improves memory. Nat Neurosci 11: 334-343.

Maggiolini M, Picard D (2010). The unfolding stories of GPR30, a new membrane-bound estrogen receptor. J Endocrinol 204: 105-114.

Maki PM (2005). A systematic review of clinical trials of hormone therapy on cognitive function: effects of age at initiation and progestin use. Ann NY Acad Sci 1052: 182-197.

Manson JE, Allison MA, Rossouw JE, Carr JJ, Langer RD, Hsia J et al (2007). Estrogen therapy and coronary-artery calcification. $N$ Engl J Med 356: 2591-2602.

McInerney EM, Weis KE, Sun J, Mosselman S, Katzenellenbogen BS (1998). Transcription activation by the human estrogen receptor subtype $\beta(\mathrm{ER} \beta)$ studied with $\operatorname{ER} \beta$ and $\mathrm{ER} \alpha$ receptor chimeras. Endocrinology 139: 4513-4522.

McMillan PJ, LeMaster AM, Dorsa DM (2002). Tamoxifen enhances choline acetyltransferase mRNA expression in rat basal forebrain cholinergic neurons. Mol Brain Res 103: 140-145.

McNair DM, Lorr M, Droppleman LF (1971). Profile of Mood States. Educational and Industrial Testing Service: San Diego, CA, USA. 
Moreira PI, Custódio JB, Oliveira CR, Santos MS (2005). Brain mitochondrial injury induced by oxidative stress-related events is prevented by tamoxifen. Neuropharmacology 48: 435-447.

Mortensen EL, Høgh P (2001). A gender difference in the association between APOE genotype and age-related cognitive decline. Neurology 57: 89-95.

Newhouse P, Newhouse C, Astur RS (2007). Sex differences in visual-spatial learning using a virtual water maze in pre-pubertal children. Behav Brain Res 183: 1-7.

Newhouse PA, Potter A, Corwin J, Lenox R (1994). Age-related effects of the nicotinic antagonist mecamylamine on cognition and behavior. Neuropsychopharmacology 10: 93-107.

Norbury R, Travis MJ, Erlandsson K, Waddington W, Ell PJ, Murphy DGM (2007). Estrogen therapy and brain muscarinic receptor density in healthy females: A SPET study. Hormone Behav 51: 249-257.

Obata T, Kubota S (2001). Protective effect of tamoxifen on 1-methyl-4-phenylpyridine-induced hydroxyl radical generation in the rat striatum. Neurosci Lett 308: 87-90.

Osborne CK (1998). Tamoxifen in the treatment of breast cancer. N Engl J Med 339: 1609-1618.

Overall J, Gorham D (1993). The brief psychiatric rating scale. Psycholo Rep 10: 799-812.

Paganini-Hill A, Clark LJ (2000). Preliminary assessment of cognitive function in breast cancer patients treated with tamoxifen. Breast Cancer Res Treat 64: 165-176.

Palmer JL, Trotter T, Joy AA, Carlson LE (2008). Cognitive effects of Tamoxifen in pre-menopausal women with breast cancer compared to healthy controls. J Cancer Surviv 2: 275-282.

Poirier J, Delisle MC, Quirion R, Aubert I, Farlow M, Lahiri D et al (1995). Apolipoprotein E4 allele as a predictor of cholinergic deficits and treatment outcome in Alzheimer disease. Proc Natl Acad Sci USA 92: 12260-12264.

Powles TJ (2012). Extended adjuvant tamoxifen for breast cancer-a new era? Lancet 381: 782-783.

Powles TJ, Hickish T, Kanis JA, Tidy A, Ashley S (1996). Effect of tamoxifen on bone mineral density measured by dual-energy $\mathrm{x}$-ray absorptiometry in healthy premenopausal and postmenopausal women. J Clin Oncol 14: 78-84.

Rossouw JE, Anderson GLInvestigators WGftWsHI (2002). Risks and benefits of estrogen plus progestin in healthy postmenpausal women. J Am Med Assoc 288: 321-331.

Rossouw JE, Prentice RL, Manson JE, Wu L, Barad D, Barnabei VM et al (2007). Postmenopausal hormone therapy and risk of cardiovascular disease by age and years since menopause. J Am Med Assoc 297: 1465-1477.

Sharma K, Mehra RD (2008). Long-term administration of estrogen or tamoxifen to ovariectomized rats affords neuroprotection to hippocampal neurons by modulating the expression of Bcl-2 and Bax. Brain Res 1204: 1-15.

Sherwin BB (2007). The critical period hypothesis: can it explain discrepancies in the oestrogen-cognition literature. J Neuroendocrinol 19: 88-81.

Shughrue PJ, Scrimo PJ, Merchenthaler I (2000). Estrogen binding and estrogen receptor characterization $(E R \alpha$ and $E R \beta)$ in the cholinergic neurons of the rat basal forebrain. Neuroscience 96: 41-49.
Silva I, LEAM Mello, Freymuller E, Haidar MA, Baracat EC (2000). Estrogen, progestogen and tamoxifen increase synaptic density of the hippocampus of ovariectomized rats. Neurosci Lett 291: 183-186.

Singh M, Meyer EM, Millard WJ, Simpkins JW (1994). Ovarian steroid deprivation results in a reversible learning impairment and compromised cholinergic function in female SpragueDawley rats. Brain Res 644: 305-312.

Tanabe F, Miyasaka N, Kubota T, Aso T (2004). Estrogen and progesterone improve scopolamine-induced impairment of spatial memory. J Med Dental Sci 51: 89-98.

Tinkler GP, Voytko ML (2005). Estrogen modulates cognitive and cholinergic processes in surgically menopausal monkeys. Prog Neuro-Psychopharmacol Biol Psychiatr 29: 423-431.

Vehmanen L, Elomaa I, Blomqvist C, Saarto T (2006). Tamoxifen treatment after adjuvant chemotherapy has opposite effects on bone mineral density in premenopausal patients depending on menstrual status. J Clin Oncol 24: 675-680.

Velazquez-Zamora DA, Garcia-Segura LM, Gonzalez-Burgos I (2012). Effects of selective estrogen receptor modulators on allocentric working memory performance and on dendritic spines in medial prefrontal cortex pyramidal neurons of ovariectomized rats. Hormones Behav 61: 512-517.

Wakade C, Khan MM, De Sevilla LM, Zhang Q-G, Mahesh VB, Brann DW (2008). Tamoxifen neuroprotection in cerebral ischemia involves attenuation of kinase activation and superoxide production and potentiation of mitochondrial superoxide dismutase. Endocrinology 149: 367-379.

Wang JM, Irwin RW, Brinton RD (2006). Activation of estrogen receptor $\alpha$ increases and estrogen receptor $\beta$ decreases apolipoprotein $\mathrm{E}$ expression in hippocampus in vitro and in vivo. Proc Natl Acad Sci USA 103: 16983-16988.

Ward HW (1973). Anti-oestrogen therapy for breast cancer: a trial of tamoxifen at two dose levels. Br Med J 1: 13-14.

Wassertheil-Smoller S, Hendrix SL, Limacher M, Heiss G, Kooperberg C, Baird A et al (2003). Effect of Estrogen Plus Progestin on Stroke in Postmenopausal Women. J Am Med Assoc 289: 2673-2684.

Weber M, Mapstone M (2009). Memory complaints and memory performance in the menopausal transition. Menopause 16: 1-7.

Woolley CS, McEwen BS (1993). Roles of estradiol and progesterone in regulation of hippocampal dendritic spine density during the estrous cycle in the rat. J Compar Neurol 336: 293-306.

Wu X, Glinn MA, Ostrowski NL, Su Y, Ni B, Cole HW et al (1999). Raloxifene and estradiol benzoate both fully restore hippocampal choline acetyltransferase activity in ovariectomized rats. Brain Res 847: 98-104.

Yaffe KM, Haan MD, Byers AM, Tangen CD, Kuller LMDD (2000). Estrogen use, APOE, and cognitive decline: evidence of geneenvironment interaction. Neurology 54: 1949-1954.

Yamamoto H, Kitawaki J, Kikuchi N, Okubo T, Iwasa K, Kawata M et al (2007). Effects of estrogens on cholinergic neurons in the rat basal nucleus. J Steroid Biochem Mol Biol 107: 70-79.

Yankova M, Hart SA, Woolley CS (2001). Estrogen increases synaptic connectivity between single presynaptic inputs and multiple postsynaptic CA1 pyramidal cells: a serial electronmicroscopic study. Proc Natl Acad Sci USA 98: 2941-3624. 